\title{
Effects of elicited reflections combined with tutor or peer feedback on self-regulated learning and learning outcomes
}

Citation for published version (APA):

Van den Boom, G., Paas, F., \& Van Merriënboer, J. (2007). Effects of elicited reflections combined with tutor or peer feedback on self-regulated learning and learning outcomes. Learning and Instruction, 17(5), 532-548. https://doi.org/10.1016/j.learninstruc.2007.09.003

DOI:

10.1016/j.learninstruc.2007.09.003

Document status and date:

Published: 01/10/2007

Document Version:

Peer reviewed version

Please check the document version of this publication:

- A submitted manuscript is the version of the article upon submission and before peer-review. There can be important differences between the submitted version and the official published version of record. People interested in the research are advised to contact the author for the final version of the publication, or visit the DOI to the publisher's website.

- The final author version and the galley proof are versions of the publication after peer review.

- The final published version features the final layout of the paper including the volume, issue and page numbers.

Link to publication

\section{General rights}

Copyright and moral rights for the publications made accessible in the public portal are retained by the authors and/or other copyright owners and it is a condition of accessing publications that users recognise and abide by the legal requirements associated with these rights.

- Users may download and print one copy of any publication from the public portal for the purpose of private study or research.

- You may not further distribute the material or use it for any profit-making activity or commercial gain

- You may freely distribute the URL identifying the publication in the public portal.

If the publication is distributed under the terms of Article 25fa of the Dutch Copyright Act, indicated by the "Taverne" license above, please follow below link for the End User Agreement:

https://www.ou.nl/taverne-agreement

Take down policy

If you believe that this document breaches copyright please contact us at:

pure-support@ou.nl

providing details and we will investigate your claim.

Downloaded from https://research.ou.nl/ on date: 26 Apr. 2023 
Running head: EFFECTS OF ELICITED REFLECTIONS

This is a pre-print of the article that was published as

Van den Boom, G., Paas, F., \& Van Merriënboer, J. J. G. (2007). Effects of elicited reflections combined with tutor or peer feedback on self-regulated learning and learning outcomes. Learning and Instruction, 17, 532-548.

http://www.elsevier.com/wps/find/journaldescription.cws home/956/description\#description

Effects of Elicited Reflections combined with Tutor or Peer Feedback on Self-Regulated Learning and Learning Outcomes

Gerard van den Boom *, Fred Paas, Jeroen J. G. van Merriënboer

Educational Technology Expertise Center, Open University of the Netherlands, Valkenburgerweg 177, P.O. Box 2960, 6401 DL, Heerlen, The Netherlands

* Corresponding author. Tel.: +31 455762329; fax: +31 455762800.

E-mail address: gerard.vandenboom@ou.nl (Gerard van den Boom). 
Effects of Elicited Reflections combined with Tutor or Peer Feedback on Self-Regulated Learning and Learning Outcomes 


\begin{abstract}
This study investigated the effects of students' reflections, combined with suggestive feedback, on the development of self-regulated learning and learning outcomes. Suggestive feedback alerts students that further reflection is advisable, without being very directive. Forty-nine students participated in a regular web-based distance education course on work psychology. In two experimental conditions students were prompted to reflect on their learning process, and received feedback on their reflections, either from peer students or a tutor. These conditions were compared to a control condition in which students studied the regular course without reflection and feedback. In line with the hypothesis, results showed that reflection combined with feedback positively affected students' self-regulated learning. In addition, students in the condition with tutor feedback outperformed students in both other conditions on learning outcomes.
\end{abstract}

Keywords: Self-regulated learning; Self-regulation; Reflection; Feedback 
Effects of Elicited Reflections combined with Tutor or Peer Feedback on Self-Regulated Learning and Learning Outcomes

\section{Introduction}

Contemporary higher education shows considerable interest in self-regulated learning (SRL). Both researchers and practitioners agree for at least two reasons that students should learn to regulate their own learning processes. At first, it is argued that SRL has a positive influence on learning outcomes (Azevedo, Cromley, \& Seibert, 2004; Masui \& De Corte, 2005; Pintrich, 2000; Thiede, Anderson, \& Therriault, 2003). Secondly, SRL is seen as imperative for acting as independent lifelong learners (Kriewaldt, 2001) and for working in future contexts in which professionals are supposed to maintain and to extend previously acquired competencies (Vermunt, 2000).

Research has shown that fostering students to become self-regulated learners is complicated (e.g., Boekaerts, 2002; Sanz de Acedo Lizarraga, Ungarte, Cardelle-Elawar, Iriarte, \& Sanz de Acedo Baquedano, 2003; Van Velzen, 2002) and should be seen as a longterm process (Pressley, 1995; Winne \& Perry, 2000). The present study was conducted to investigate the effect of students' reflective activities on the development of their SRL. Reflective activities arise while thinking over things that have happened during the learning process and thinking about learning, teaching, learning activities, and learning experiences in general (Vermunt \& Verloop, 1999), and while considering alternatives. Students' reflective activities were evoked by means of prompts and resulted in electronic reflective messages. Feedback provided by either a tutor or peer students was used to intensify the reflective activities. Effects on SRL, learning outcomes, and students' opinions about the studied course were examined. 


\subsection{Self-regulated learning (SRL)}

SRL can be defined as the active and constructive process that makes learners responsible for their own learning. There is broad consensus that SRL comprises many aspects related to students' learning, such as goal setting, using effective strategies to organize learning, monitoring performance, self-awareness, motivation, and holding positive beliefs about capabilities (e.g., Boekaerts, 1999; Pintrich, 2000; Zimmerman \& Schunk, 2001). It is essential for SRL that students are in a position to take responsibility for their own learning, and are able to act as self-regulated learners, which means that they potentially are competent to shape their learning according to their own purposes and actively modulate their learning to changing circumstances (Pintrich, 2004).

For the present study SRL is decomposed using the method of principled skill decomposition (Van Merriënboer, 1997). The decomposition resulted in a SRL profile chart, presented in Figure 1, in which all SRL-related constituent components and cognitive, affective, planning, and contextual aspects are brought together. In accordance with Zimmermann (1998), the SRL process is represented in three phases. At the first level of decomposition, the main phases of the SRL process are: The starting phase, the performing phase, and the finishing phase of the learning process (see Figure 1, left column). For selfregulated learners this indicates that, potentially, they are supposed to be able to start learning processes by themselves, to perform learning activities by themselves, and to finish their own learning processes.

\section{****** INSERT FIGURE 1 ABOUT HERE}

On the second level of decomposition (Figure 1, second column) the schema shows that in the 'starting phase' self-regulated learners are supposed to be able to execute an orientation and to draw up a planning. In the 'performing phase' self-regulated learners are supposed to be able to monitor their learning process, and to adjust their learning activities if 
necessary. In the 'finishing phase' students are supposed to be able to execute an evaluation of the learning process.

The third level of decomposition (Figure 1, third column) shows the aspects to which the orientation, planning, monitoring, adjusting, assessing, and evaluation are directed. These aspects are derived from the SRL framework of Pintrich (2000), the SRL models of Boekaerts (1997) and Winne and Hadwin (1998), and from the multidimensional approach of learning competence presented by Masui and De Corte (2005). In all steps of the SRL process students have to deal with aspects of the study tasks (task aspects), personal aspects of her or himself (self aspects), aspects of the learning context (contextual aspects), and planning aspects. For instance: During the orientation students should be able to consider the relevant task aspects such as the learning goals, the necessary cognitive processing strategies (e.g., analyzing, memorizing, and applying), the required time, resources, study environment, and the required prerequisite knowledge. Orientation on self-aspects is concerned with motivation, learning intentions, self-efficacy, and valuing of the task. Planning starts with the confrontation of the results of the task, self, and context diagnoses that were executed during the orientation. The step labeled 'confront diagnoses' deals with the consideration and adoption by students of learning goals, the check of the fit of the required prior knowledge and the actual prior knowledge state, the check and adjustment of affective aspects such as motivation and volition for learning. In the planning phase, a student adopts a study task as such, modifies a study task before adopting it, or designs a new own study task. In the monitoring and adjustment activities during the execution of study tasks, for instance, the 'task aspects' deal with the perceived appropriateness of the cognitive learning strategies that were used. An example of monitoring a 'self aspect' is the check of the motivation, the concentration and the self-efficacy with which a student performs a study task. And for instance, the evaluation of 
'self aspects' deals with the attribution of experiences of failure and success, and the valuing of efforts, motivation, and volitional experiences during the study process.

It is important to realize that although Figure 1 may suggest that SRL is a linear process, the feedback loop (presented here only on the highest level of decomposition) makes clear that SRL in fact is a dynamic and iterative process. Experiences and outcomes of later phases and steps should be considered as feedback and input for preceding steps that should be executed again to readjust the process. For example, within the performing phase all kinds of adjustments, indicated by monitoring processes can be carried out regarding the executing of the study task. And, for instance, learning goals can be adjusted because of lack of time, or a planning can be adjusted because of newly stated learning goals.

\subsection{Prompts and feedback: Ingredients to stimulate students' reflective activities}

Research has shown that reflective thinking is a crucial activity to foster the development of students' ability to SRL (Butler, 2003; Schunk \& Ertmer, 2000; Van Velzen, 2002; Winne \& Perry, 2000; Zimmerman, 1998, 2001). In accordance with Van Manen (1991), we conceive reflective thinking in some sense as just another word for thinking; "Reflection in the field of education carries the connotation of deliberation, making choices, coming to decisions about alternative courses of action" (Van Manen, 1991, p. 511). Reflection makes students aware of their experiences in learning processes. They become aware of what they did or should have done, and of what and how to do next. Related to the SRL schema of Figure 1, reflection during the starting phase can be labeled as "forethought" (cf., Zimmerman, 1998). Reflective activities during the performing phase and finishing phase can be labeled as "intermediate thought" and "afterthought", respectively. Both Ertmer and Newby (1996) and Van Velzen (2002) concluded that reflection might result in a coherent and useful personal store of learning related skills and knowledge that might guide future learning actions. This was confirmed by others, who reported that by reflecting learning experiences 
were interpreted and that these interpretations were incorporated into personal mental models of learning and studying (Lee \& Hutchison, 1998; Seale \& Cann, 2000; Von Wright, 1992).

While there is a broad consensus that reflection is a crucial factor for the improvement of students' SRL, it is found at the same time that in educational practice most students do not reflect spontaneously on their learning processes (Van Velzen, 2002). To overcome this lack of spontaneous reflections, additional educational measures that stimulate students to reflect on their learning processes can be considered. Prompting has been identified as a promising method to evoke these reflective activities (Butler, 1998; Chi, De Leeuw, Chiu, \& LaVancher, 1994; Lee \& Hutchison, 1998; Sobrol, 2000, Van den Boom, Paas, van Merriënboer, \& van Gog (2004). Therefore, in this study 'reflection prompts' were applied to stimulate students to reflect on their learning processes.

In educational settings feedback has proved to be adequate to improve the progress of students' learning and to deepen learning processes (Chi, 1996; Mory, 2003). In a setting where reflection is used as a means to foster students' SRL, external feedback can play a role to ensure that the process of reflection remains adequate (Butler \& Winne, 1995; Mory, 2003; Winne \& Hadwin, 1998). If students' reflections threaten to result in misconceptions about tasks, self, context, or used strategies, external feedback becomes essential. External feedback offers opportunities to broaden and deepen the perspective that students get on themselves when they reflect on their own experiences. Therefore, in this study, in addition to reflection prompts that merely stimulate reflection, external feedback on students' reflections is planned as a means to increase the quality of reflective activities. This combination is expected to contribute to the development of SRL. Concerning the external feedback, two important factors are at issue: The type of feedback, and the source of the feedback.

To define the type of feedback that could be dealt with in relation to reflective activities more precisely, we used the distinction of Chi (1996) between three types of 
feedback: Corrective feedback, didactic explanations, and suggestive feedback. In the present experiment we focused on the possible effects of suggestive feedback. Suggestive feedback alerts the student that there is a problem, without telling exactly what the problem is. Examples of suggestive feedback are questions such as "Can you explain why you did it that way?", or observations like "I don't think you should do it that way", or references to new information such as "Have you thought of - - - ". This type of feedback was expected to launch a successive series of reflective activities. In other words, combining students' reflections with external suggestive feedback was expected to be a promising way to increase the impact of the reflective activities, so that it fosters students' SRL abilities.

With regard to the feedback source the question is: Who should provide the feedback? In educational settings, feedback is usually provided by teachers or tutors. Because tutor feedback has proven to be adequate (Chi, 1996; Mory, 2003), it was decided to apply tutors as a promising source of the external feedback intended to strengthen the impact of reflection. And, because several studies have found indications for peer feedback to be effective too (Bangert-Drowns, Kulik, Kulik, \& Morgan, 1991; Dochy, Segers, \& Sluijsmans, 1999; Falchikov, 1996; Kriewaldt, 2001), it was decided to use peer students as a second source of external feedback, and to compare the effects of feedback provided by tutors with feedback provided by peer students. Concerning SRL, tutors are considered to be better equipped to provide feedback than peer students. Tutors act more detached and objective, whereas peer students are more emotionally involved and may therefore provide less direct and concrete feedback (Nilson, 2003).

\subsection{The present study and hypotheses}

In this study, the effectiveness of students' reflective activities for the development of their SRL abilities was investigated. Two experimental conditions were compared to a control condition. In all conditions, students of a distance teaching university studied a regular course. 
In the two experimental conditions students were provided with reflection prompts intended to evoke reflections on their learning processes. In addition to these prompts, in one experimental condition feedback from peer students was planned; in the other experimental condition feedback from a tutor was planned. The students in the control condition studied the regular course without reflection prompts and feedback.

The research questions were: (1) Do reflection prompts result in reflective activities? (2) Does external feedback, provided by peer students or a tutor, intensify students' reflective activities? (3) Are students' reflective activities, combined with peer or tutor feedback, beneficial for the development of students' SRL and learning outcomes? Based on theoretical and empirical considerations, it was expected that the experimental conditions would lead to higher development of students' SRL than the control condition. Moreover, it was expected that the type of feedback (peer vs. tutor) would differentially affect the development of SRL. It was expected that the impact of tutor feedback would be more powerful than the impact of peer feedback. In addition to the questions related to SRL, it was explored whether a positive relation between the development of SRL and learning outcomes (Azevedo \& Cromley, 2004; Pintrich, 2000; Thiede et al., 2003) could be confirmed.

\section{$2 \quad$ Method}

\subsection{Participants}

Participants were 84 regular students at a distance teaching university who were free to plan their studies in accordance with their own personal possibilities and constraints, only restricted by the time boundaries of the experimental period of nine months. They were randomly assigned to one of the three conditions. Eventually, 49 students (58\%), 36 women and 13 men (mean age $=38.7$ years, $S D=7.8$ years $)$ completed all activities within the ninemonth period of the experiment, resulting in the following division over the three conditions: control condition: $n=18$, peer feedback condition: $n=16$, and tutor feedback condition: $n=$ 
15. For the course that was used in the experiment, the normal drop out rate is about $40 \%$, within the first year of enrolment. Main reasons for drop out during the experimental period concerned personal circumstances like illness, marriage, divorce, becoming unemployed, or finding another job. Given the authentic, regular study setting of the experiment, complications and disadvantages concerning experimental control caused by the drop out were considered as inevitable and acceptable.

All participants who completed the experiment were offered a reimbursement of $€ 20$ for extra expenses such as the use of Internet. In addition, at the end of the experiment, these participants took part in a lottery in which two participants could win a weekend trip to Paris.

\subsection{Materials}

\subsubsection{Study environment and course}

In this study the development of students' SRL is considered in the context of distance education at university level. To meet the criteria of ecological validity, and Pressley's (1995) concern that the development of SRL is a long-term process, it was decided to conduct the experiment in the authentic study setting of a regular distance education course with an estimated study load of 120 hours. The experiment was conducted within Study Net, the webbased electronic learning environment of the Open University of the Netherlands. The second edition of the course Introduction to Work Psychology (2002) was used. The course consisted of a textbook (Arnold, Cooper, \& Robertson, 1998) and additional study materials: A CDROM with audiovisual and textual materials, an electronic workbook implemented in Study Net, and a paper course brochure. Also a reader was available, both in paper and in electronic form as part of the electronic workbook. The purpose of the electronic workbook was to support the students to study the content of the textbook and to utilize this content for the analysis of case materials. The electronic workbook was subdivided into seven thematic study tasks (see Table 1). The authenticity and size of the course made it reasonable to expect that 
all aspects of SRL were relevant, both on the level of the complete course and on the level of the constituent study tasks.

\subsubsection{Reflection protocol}

To investigate the impact of reflection in combination with external feedback, i.e., the reflection protocol, a tutoring frame as used by Chi (1996) and Graesser, Person, and Magliano (1995) was embedded. This protocol offered the opportunity to realize reflective dialogues between the student and external feedback providers. Reflective dialogues are defined as iterative processes in which reflections are elaborated on. For the use within an electronic learning environment the tutoring frame as used by Chi (1996) was modified to a protocol containing the following five steps: (1) Students are prompted to evoke reflection on aspects of their learning process, by means of reflection prompts (RPs) that are built in the study tasks; (2) Students generate a reflection note in a structured electronic format (emessage); (3) External feedback on the reflection note is provided (e-message); (4) The reflection is elaborated on in a successive series of exchanges (reflective dialogue) between the student and the feedback provider; and, (5) The students' understanding is assessed.

Students in the control condition studied the regular version of the course. No measures related to the reflection protocol were embedded in this regular course. For the two experimental conditions modifications were made to the regular course. In the modified versions of the electronic workbook a series of nine reflection prompts (RPs) was presented to the students as parts of supplements to the seven thematic study tasks. The RPs were designed comparable with other assignments in the course. The RPs were presented as web pages in the electronic workbook, each on a separate form. In Table 1 the study tasks, the RPs, and the aspects of SRL that are reflected upon are schematically presented. 
The first two RPs concerned aspects of the starting phase. RPs 3 to 7 were related to aspects of monitoring and adjusting activities in the performing phase. And the last two RPs (8 and 9) were related to evaluative aspects in the finishing phase. It was decided not to implement more than these nine RPs, to keep a reasonable balance between the learning activities that the students are expected to do while studying the regular course, and the supplementary reflective activities.

When the students in the peer feedback condition or in the tutor feedback condition studied the course, they were automatically confronted with the successive RP in their electronic workbook. The students had to formulate their reflections in text areas that were part of the forms (web pages) that presented the RP. By clicking on the send-button the reflections were sent as electronic messages (e-message) either to the electronic newsgroup in which the students participated (peer feedback condition), or to the e-mailbox of the personal tutor of the student (tutor feedback condition).

\subsubsection{Peer feedback}

The students in the peer feedback condition were assigned to electronic newsgroups on the basis of their starting date. There was a January newsgroup, a February newsgroup, a March newsgroup and a newsgroup for students who started later. The groups contained 6 to 8 students each. The students were instructed to moderate their own newsgroup. In the peer feedback condition students were urged to provide feedback on the reflections of their fellow students. The instruction to submit feedback was placed as a message in the electronic newsgroup, and furthermore every web page with an RP contained the invitation to the peer group students: "Please read the answers of your fellow students, and formulate a reaction to it. Moreover, read the reactions that your fellow students present on your answers". The students were suggested to base their feedback also on their own experiences with the same study tasks, and their own reflections on the RP concerned. This suggestion was given to 
stimulate the sharing of experiences. And, although not based on typical SRL expertise, this type of feedback is expected to be valuable for all the students in the newsgroup, because it might stimulate the development of a common basis of experiences.

\subsubsection{Tutor feedback}

Whereas the students in the peer feedback condition were assigned to newsgroups, the students in the tutor feedback condition were randomly assigned to one of the four tutors that contributed to the course; so 7 students were assigned to each tutor. The students in this condition received electronic feedback by e-mail. It was agreed that the tutors should send their feedback massages within 48 hours after receiving a reflection from a student. The tutors were educational technologists at the Open University and experienced in tutoring students. The tutors participated in a 2-hours training session to become familiar with their specific tutoring task in the experiment. They were provided with documentation about the SRL decomposition, and the rationale of the experiment was discussed collectively. During the experiment the tutoring procedures and tutoring experiences were discussed more in depth in several meetings of the tutors and the research team.

\subsection{Measurement instruments}

\subsection{1. $S R L$}

In this study, the development of students' SRL was measured by means of the Motivated Strategies for Learning Questionnaire (MSLQ; Pintrich, Smith, Garcia, \& McKeachie, 1991, 1993), which was translated into Dutch. Winne and Perry (2000) referred to the MSLQ as a usable questionnaire for the measurement of SRL as an aptitude. The MSLQ is an instrument designed to assess students' motivational orientations and their use of different learning strategies. Because the MSLQ is a self-report instrument, it measures the perception of the students rather than their SRL behavior. Reported developments should be interpreted accordingly. 
The MSLQ consists of a motivation section and a learning strategies section. The motivation section, that refers to students 'self-aspects', includes the Value scale, with 3 subscales focusing on the reasons why students engage in an academic study (Intrinsic motivation, Extrinsic motivation, and Task value), the Expectancy scale with subscales that refer to students' beliefs about their ability to accomplish a task (Control beliefs about learning, and Self-efficacy for learning and performance), and the Test anxiety scale operationalized in terms of items related to students' worry and concern over taking exams. The learning strategies section includes the Cognitive strategy scale, referring to the core of the learning processes (containing 4 subscales: Rehearsal, Elaboration, Organization, and Critical thinking), the Resource management strategies scales referring to students' strategies to control contextual and planning aspects (Time and study environment, Effort regulation, Peer learning, and Help seeking), and the Metacognitive strategy scale, referring to the control and regulation of the cognitive learning processes. This Metacognitive strategy scale includes items referring to goal setting, monitoring of comprehension, and adjusting reading speed depending on the task. For the analysis of the development of students' SRL these 6 MSLQ scales were used because of their conformity with the SRL schema.

The MSLQ consists of 81 items that must be scored on a 7-point Likert scale, ranging from (1) "Not at all true of me" to (7) "Very true of me". Reliability and validity of the questionnaire have been thoroughly investigated and confirmed by Pintrich et al. (1991, 1993). The translated Dutch version was analyzed based on the responses of 260 students. Two items were removed because they correlated negatively with the remaining items of the two subscales to which they were supposed to belong, and caused a decrease of the alpha reliability coefficient for the respective subscales Intrinsic goal orientation (item 24) and Metacognitive self-regulation (item 57). So the Dutch version of the MSLQ used in this study consisted of 79 items. 
An overview of the scales and subscales of the MSLQ, and Cronbach's alpha reliability coefficients as found for our data are presented in Table 2. For the fifteen subscales the Cronbach's alpha reliability coefficients are presented both for the original version, and for the translated Dutch version.

****** INSERT TABLE 2 ABOUT HERE $* * * * * *$

\subsubsection{Learning outcomes}

To assess the learning outcomes the regular examination of the course was used. The students had to make an appointment to take the examination when they judged themselves to be sufficiently prepared. For every student a random sample of 40 items was selected from the course item bank that consists of 800 items. The items are of the multiple-choice type containing a stem (a question or a statement) and four responses. In accordance to the educational system of the Open University test performances are converted to a performance score on a 10-point scale. Therefore, student performances are reported as a learning outcome score between 1 (the minimal score) and 10 (the maximum score).

\subsubsection{Evaluation questionnaire}

To determine students' appreciation of the course, the reflection prompts, the reflective activities, the feedback, the tutors, and the newsgroups with peer students, the student opinions were collected by means of an evaluation questionnaire. For each item the students could indicate to what extent they agreed to it. Most items were accompanied by a 5-point Likert scale, ranging from (1) "I totally disagree" to (5) "I totally agree". Additionally, a few other questions were posed: One question to get information about students' perceived study load of the course, and the request to score the quality of several parts of the course on a 10point scale $(1=$ extremely poor, $10=$ excellent $)$. 


\subsubsection{Loggings}

Participants were supposed to note down all their conducted study activities (what, when, how long) in a diary. Time-on-task was registered in a logbook, both for the study by the students and for the tutoring by the tutors. All electronic reflective activities were logged in Microsoft Outlook email for the tutor feedback condition, and in Microsoft Outlook newsgroups for the peer feedback condition.

\subsection{Procedure}

All students enrolled in the course "Introduction to Work Psychology" for the same academic year were requested to complete the MSLQ (Pintrich et al., 1991), and invited to participate in the experiment that was planned to start in January in that academic year. This request resulted in a response of 260 students. Completion of the MSLQ was seen as the pretest (MSLQ1) of students' SRL. From the responding group, 84 students who indicated that they were able to study the course within the time boundaries of the experiment were selected and randomly assigned to one of the three conditions. Participants in the control condition studied the regular course. Participants in the peer feedback condition studied the modified course with the reflection protocol including peer feedback. Participants in de tutor feedback condition studied the modified course with the reflection protocol including tutor feedback.

After the students had finished the course by taking the course exam, they had to send in their diary. On receipt of the diary the MSLQ, the Evaluation questionnaire, and the declaration of expenses were sent to the students. The students finished the experiment by returning the completed MSLQ and Evaluation questionnaire. This second completion of the MSLQ was seen as the posttest (MSLQ2) of students' SRL. 


\section{Results}

\subsection{Reflective activities}

To answer the questions whether reflection prompts resulted in the intended reflective activities, and whether the reflective activities could be intensified by means of providing external feedback, the loggings of the reflective activities were analyzed. Table 3 presents the number of initial reflective messages from the students on the RPs, and the number of electronic messages in the reflective dialogues, for the peer feedback condition and the tutor feedback condition, respectively.

\section{***** INSERT TABLE 3 ABOUT HERE}

The loggings of the reflective activities of the students in the peer feedback condition showed a total of 107 initial reflective messages, indicating that the students in this condition initially produced 6.7 out of 9 possible reflective messages (on the nine RPs) on average. For the students in the tutor feedback condition the registration revealed a total of 132 initial reflective messages, indicating that students in this condition initially produced 8.8 out of 9 possible reflective messages on average. Chi-square test indicated that the difference of initial reflections between the two conditions was not significant, $\chi 2(1, N=18)=2.05, p<.20$.

The total number of electronic messages, as an indication for overall reflective activities in the peer feedback group was 118 , indicating an average of 7.4 messages for the students in this condition. The total number of electronic messages, as an indication for the overall reflective activities in the tutor feedback condition was 416 , indicating an average of 27.7 messages for the students in this condition. A Chi-square test, applied to compare the peer feedback group and the tutor feedback group, revealed that they differed significantly concerning the total number of reflective activities, $\chi 2(1, N=773)=41.13, p<.001$.

These quantitative results indicate that the RPs resulted in initial reflective activities in both feedback conditions. Moreover the results indicate that in the peer feedback condition 
hardly any reflective dialogues occurred, whereas in the tutor feedback condition the reflective activities actually developed into the intended reflective dialogues. These findings should be taken into account while interpreting the findings regarding the developments on students' SRL and their learning outcomes.

\subsection{Effects on SRL and learning outcomes}

To determine whether reflective activities differentially affected the development of students' SRL and learning outcomes, and whether the two feedback modalities were differentially effective, the dependent variables under analysis were the development on aspects of SRL, and the learning outcomes. Development on aspects of SRL was inferred from MSLQ data. On the MSLQ (pretest and posttest), students reported twice their perceptions concerning aspects of SRL. These measures were converted into difference scores (MSLQ2 - MSLQ1) for the respective MSLQ scales. Descriptive statistics of the dependent variables (and some other course related scores) are presented in Table 4.

\section{****** INSERT TABLE 4 ABOUT HERE}

The data concerning MSLQ and learning outcomes were analyzed with one-way ANOVA with independent groups. An alpha level of .05 was used for statistical significance tests. The partial-eta-squared statistic was used as an effect size index, where values of .01, .06 , and .14 correspond to small, medium, and large values, respectively (Cohen, 1988). Planned contrasts, using Bonferroni's correction, were conducted to analyze the differences between the experimental conditions.

\subsubsection{Development of $S R L$}

The first step in the analysis of the development of SRL was to determine whether the three experimental groups differed for their initial scores on the MSLQ. An ANOVA on the MSLQ pretest (MSLQ1) revealed no significant differences for any of the six MSLQ scales, Value scale, $F(2,46)=.35, n s$; Expectancy scale, $F(2,46)=.58, n s$; Test anxiety scale, $F(2$, 
$46)=.12, n s ;$ Cognitive strategy scale, $F(2,46)=2.27, n s$; Metacognitive strategy scale, $F(2$, $46)=1.23, n \mathrm{~s}$, and Resource management strategy scale, $F(2,46)=.20, n s$. Based on these findings it can be concluded that the initial SRL of the three groups in the experiment did not differ.

Subsequently, students' development on aspects of SRL (MSLQ2 - MSLQ1) was analyzed at the level of the six MSLQ scales. An ANOVA on the difference scores yielded a significant main effect of the experimental conditions on the Value scale, $F(2,46)=5.98$, $M S E=.15, p<.01, \eta^{2}=.21$, and on the Test anxiety scale, $F(2,46)=3.28, M S E=.56, p<$ $.05, \eta^{2}=.13$. No significant main effects were found for the other four MSLQ scales, all $F_{\mathrm{S}}<$ 1.0. The effect found for the Value scale indicates that the students in the three groups differed for their development on the SRL aspects that concern their motivation for the study, and their judgment of the study in terms of interest, importance, and utility. The students in the control condition $(M=-.26, S D=.36)$ showed a negative development, whereas the students in the peer feedback condition $(M=.14, S D=.41)$ and the students in the tutor feedback condition $(M=.13, S D=.38)$ showed a positive development on the value related aspects. Contrast tests revealed a significant difference between the students in the control condition and the combined mean of the students in the two feedback conditions, $t(46)=3.46$, $\mathrm{p}<.01$. This finding is in line with the expectation that reflective activities affect the development of students' SRL. The contrast between the peer feedback condition and the tutor feedback condition was not significant, $t(46)=.07, n s$, indicating that there was no effect of feedback type on the development of the value aspects of SRL.

The effect found for the Test anxiety scale indicated that the students in the three groups differed for the development of their anxiety to take the examination. Contrast tests revealed no significant difference for the test anxiety scores between the students in the control condition $(M=.26, S D=.65)$ and the students in the peer feedback condition $(M=$ 
$.24, S D=.71), t(46)=.07, p=.94$. On the other hand, the contrasts between the tutor feedback condition $(M=-.35, S D=.89)$ and the peer feedback condition, $t(46)=2.17, p<$ .05 , and between the tutor feedback condition and the control condition, $t(46)=2.30, p<.05$, were significant. These findings indicate that students in the control condition and in the peer feedback condition showed a negative development on this affective aspect of students' SRL; their test anxiety increased. The students in the tutor feedback condition showed a positive development on this aspect; their test anxiety decreased. For Test anxiety not the initial reflection, but the tutor feedback and the resulting reflective dialogues thus appeared to cause the differences.

\subsubsection{Learning outcomes}

An ANOVA on the learning outcomes yielded a significant main effect of condition on learning outcomes, $F(2,46)=3.23, M S E=1.93, p<.05, \eta^{2}=.12$. Contrast tests revealed no significant differences between the mean learning outcomes of the students in the control condition and the combined mean learning outcomes of the students in the two feedback conditions, $t(46)=0.96, n s$. The contrast between the peer feedback condition and the tutor feedback condition was significant, $t(46)=2.37, p<.05$, indicating that the tutor feedback condition $(M=6.93, S D=1.09)$ outperformed the peer feedback condition $(M=5.75, S D=$ 1.34). Additional contrast tests revealed that the mean learning outcomes in the tutor feedback condition was significantly higher than in the control condition, $t(46)=2.04, p<.05$, whereas the mean learning outcomes of the peer feedback condition and the control condition did not differ, $t(46)=0.41, n s$. As for Test anxiety, for the learning outcomes differences also do not appear in consequence of initial reflection, but only in consequence of the reflective dialogues that occurred in the tutor feedback condition. 
An ANOVA on time-on-task revealed no significant differences, $F(2,46)=0.63, n s$, indicating that the observed differences of the learning outcomes cannot be imputed to the factor study time.

To obtain more insight in the hypothesized correlation between students' SRL and learning outcomes, Spearman rank correlation coefficients were computed for the entire sample $(N=49)$. Results showed a significant positive correlation between learning outcomes and the Expectancy scale $\left(r_{s}=.26, p<0.05\right)$, and a significant negative correlation between learning outcomes and the Test anxiety scale $\left(r_{s}=-.29, p<0.05\right)$ as measured by the MSLQ (posttest). For the other four subscales no significant correlations were found.

\subsection{Evaluative opinions}

The evaluation question concerning the overall evaluative opinion about the introduction course to work psychology (scored on a 10-point scale) yielded an overall positive opinion of all participants about the course $(M=6.93, S D=0.73)$. The three conditions did not differ significantly in their overall opinion, $F(2,46)=0.18$, $n s$ (see bottom part of Table 4). The evaluative question concerning the overall opinion about the experienced feedback modality showed that students in the peer feedback condition $(M=$ 4.60, $S D=2.03)$ and the tutor feedback condition $(M=8.27, S D=1.22)$ differed significantly in their opinion, $t(28)=5.99, p<0.001$. Students in the tutor feedback condition were more positive than students in the peer feedback condition.

The students in the two feedback conditions were asked to score a set of more specific evaluative questions with respect to the type of feedback they were confronted with in their condition. The results for these questions are presented in Table 5.

****** INSERT TABLE 5 ABOUT HERE ******

The usefulness of the reflection prompts was positively rated in both feedback conditions. Similar results were found with regard to the students' opinion about the reflection 
prompts as a stimulus to reflect on the study process. The evaluation of the reflection prompts as distracting for the learning process yielded neutral opinions for both feedback conditions. The $t$-tests for these issues revealed that students in the peer feedback condition and students in the tutor feedback condition did not differ in their evaluations of the usefulness of the reflection prompts, $t(28)=0.79, n s$, the reflection prompts as stimuli to reflect, $t(28)=0.57$, $n s$, and the reflection prompts as distracting, $t(28)=0.13, n s$.

\section{Discussion}

The goal of this study was to determine (1) whether reflection prompts could result in the intended reflective activities, (2) whether the students' reflective activities could be intensified by external feedback provided by peer students or a tutor, and (3) whether students' reflective activities, combined with peer feedback or tutor feedback, could be beneficial for the development of students' SRL and learning outcomes.

With regard to the first research question, the results show that providing students with reflection prompts resulted in participation in initial reflective activities. Therefore, we conclude that reflection prompts are suitable to evoke the intended initial reflective activities by the students. This finding confirms the theory that indicated prompting as a promising method to evoke reflective activities from students (Butler, 1998; Chi, De Leeuw, Chiu, \& LaVancher, 1994; Lee \& Hutchison, 1998; Sobrol, 2000).

With regard to the second research question, it can be concluded that providing feedback on their initial reflections intensifies the reflective activities of the students. However, for the two feedback modalities that were implemented in the reflection protocol, the effects were quite different. In both feedback conditions (peer feedback and tutor feedback) the reflection prompts resulted in the intended initial reflections, but the more extensive reflective activities leading to reflective dialogues only occurred when the external feedback was provided by a tutor. Logging data showed that the students in the peer feedback 
condition hardly provided each other with the intended feedback, if at all. This finding made it reasonable to exclude the peer feedback condition from the analyses, or, to redefine this condition. We did choose for the second option. The peer feedback condition is redefined and conceived as the "reflection-without-feedback" condition. In the control condition students received no reflection prompts. In the reflection-without-feedback condition, students were provided with reflection prompts, and reflected on their study process on their own. They sent their reflections to a newsgroup, but other newsgroup members did not actively co-reflect. In the tutor feedback condition students received reflection prompts. These students reflected on their study process and they sent their reflections by e-mail to a tutor. The tutor provided feedback; actually the tutor acted as a co-reflector. Only in this last condition reflective dialogues occurred.

The observation that students did not provide feedback to their peer students raises the question concerning possible circumstances and possible methods by which students can be stimulated to act as co-reflectors. To answer this question further research with other designs for reflection protocols with peer feedback is needed. Because reflective dialogues in which peer students act as co-reflectors can be conceived as collaborative processes, consequently, it is well possible that theories on collaborative learning (Johnson \& Johnson, 1999; Strijbos, 2004; Strijbos, Kirschner, \& Martens, 2004) offer practical measures to boost the reflection protocol with peer feedback. For the issue of collaborative reflective activities, this leads up to some interesting questions for future research. For instance, such research should try to determine how more positive interdependence between students can be created, how a balance between students' investments in and profits from participation in reflective dialogues can be realized, and how much support and encouragement students need to become able and willing to provide their peers with feedback on their reflections. 
With regard to the third research question, results show that the students in the three conditions differed regarding their development of the motivational aspects of SRL. The three groups differed significantly for their development on two of the six scales of the MSLQ. On the Value scale a positive developmental effect was found for the reflection-without-feedback condition and for the condition with tutor feedback, whereas students in the control condition showed a negative development. Contrast test between the combined reflection conditions (reflection-without-feedback and tutor feedback) and the control condition indicated that these differences were significant. This finding provides evidence that reflection alone is enough to bring about a positive developmental effect on the value aspects of the MSLQ. Differences were also found for the Test anxiety scale. With regard to test anxiety a decrease was found for the students in the tutor feedback condition. The students in the tutor feedback condition appeared to become more self-confident, whereas the test anxiety of students in the control condition and the reflection-without-feedback condition increased.

Consistent with what was expected, students who received feedback on their initial reflections and who developed reflective dialogues, showed a higher development of their SRL than students in the control condition. In this experiment, the treatment with tutor feedback has proven to be the most powerful one for the development of students' SRL. On two MSLQ scales, the Value scale and the Test anxiety scale, developments in the tutor feedback condition and the control condition were in the opposite direction and significantly different. The students who reflected in response to the reflection prompts, but who did not further engage in reflective dialogues, differed from the control group only for their development on the Value scale. This is consistent with Butler and Winne (1995), who stated that internal feedback needs to be complemented with external feedback for SRL to develop. However, because the students in the reflection-without-feedback and the tutor feedback condition did not differ on their score on the value scale, we can conclude that initial 
reflective activities may already be sufficient to lead to developments on the value aspects of SRL. A noticeable point in relation to the conclusions on developments on SRL is that the found differences only concerned two aspects of the motivation section of the MSLQ. No differences were found for the Expectancy scale of the motivation section, or for the learning strategies section of the MSLQ. A possible explanation for this finding can be found in the design of the course used in the experiment. This design is quite inflexible, and seems to insufficiently challenge students to use alternative learning strategies. In general, further research on determinants of the variability and consistency of students' SRL is advisable to gain more insight into this issue.

With regard to the exploration of possible differences between learning outcomes in the three conditions, results showed that the students in the tutor feedback condition outperformed the students in the other two conditions on the final examination. It was also found that students in the reflection-without-feedback condition did not score better on the final examination than the students in the control condition. Based on these findings we conclude that initial reflections in response to the Reflection prompts are not sufficient to positively affect the learning outcomes.

The relationship between SRL and learning outcomes is difficult to interpret on the basis of the present results. The theoretically assumed positive relationship between SRL and learning outcomes (Azevedo \& Cromley, 2004; Pintrich, 2000; Thiede et al., 2003) was supported by the positive correlations between learning outcomes and two of the six MSLQ scales, the Expectancy scale and the Test anxiety scale. An explanation for the fact that no correlation was found between learning outcomes and the other four MSLQ subscales possibly can be found in an insufficient matching between the SRL aspects (see Figure 1) on which the reflection prompts are based and the subscales of the MSLQ. This matching problem should be further investigated so that reflection prompts and SRL measurement can 
become better attuned. In addition, such investigation could throw light on the present finding that no development on SRL was found for the Expectancy scale, in combination with a positive correlation between the Expectancy scale and learning outcomes. It is clear that more research is needed into the relationships between SRL and learning outcomes. A better tuning between the theoretical model and the measurement instruments is needed. Path analysis and structural equation modeling are promising techniques to determine to what extent intervention-induced changes in aspects of SRL could be associated with course-related variables, such as learning outcomes, and to test the mediating variables reflection activities and feedback in the two modalities.

Another issue that is interesting for further research concerns the content of reflections. A research path that could be helpful to the investigation of the effects of reflection and feedback on the development of SRL deals with the content analyses of reflective messages and reflective dialogues. Such methods might help us to triangulate measurements (Weinstein \& Meyer, 1996; Winne \& Perry, 2000). A combination of qualitative and quantitative analyses of reflective activities possibly enables us to reveal why the tutor feedback condition produced superior learning performance and better performance on two of the six MSLQ subscales, and why the students in the reflection-without-feedback condition did little or no better than control students on the various measures.

\subsection{Instructional implications}

Notwithstanding the fact that several questions are not yet answered and call for further research, we will present some instructional implications. Our results have implications for the design of electronic learning environments intended to foster students' SRL. We conclude that it is beneficial to present prompts to students that evoke them to reflect on their learning processes. It should be made explicit to the students that their reflections help to gain better learning outcomes. A direct application of the results would be 
for developers of distance education courses to embed a reflection protocol in their courses. Reflection prompts could be extracted from the SRL schema as presented in the introduction to this article. The listed aspects of SRL can be helpful to formulate a series of reflection prompts. For the communication between tutors and students, or between students and their peers, easily accessibly electronic communication tools should be made available within the electronic learning environment.

In connection with reflective activities the educational concept of process-oriented instruction offers a valuable starting point (Vermunt, 1998). In accordance with the rationale of process-oriented instruction students' acquisition of SRL can profit from the approach that is typified by the gradual transfer of the responsibilities concerning the regulation of the learning processes from the teacher to the students (i.e., 'scaffolding'; Vermunt \& Verloop, 1999). It is essential that the activities of mutually providing feedback are well integrated into the instructional design. Moreover, the providing of feedback to each other needs to be trained (Sluijsmans, 2002). For adult students this might take the form of gradual withdrawal of the tutor, combined with a gradual increase of peer participation. The tutor starts as the model for providing feedback, and the tasks concerning the provision of the feedback are gradually handed over to the students.

\subsection{Limitations}

We will point at three limitations of this study. First, a limitation of the design of the study is that the tutor condition and the peer feedback or reflection-without-feedback conditions differ in many ways besides providing feedback. For example, students in the reflection-without-feedback group posted their reflections in an electronic newsgroup, whereas in the tutor feedback condition the tutors worked directly with the students in e-mail conversations. Therefore, the conditions also differed for students' opportunity to read each other's contributions. Thus, effects of the different communication channels could also or 
partly have been the cause of the reported results. The lack of experimental control in this experiment within the authentic study setting is understandable from a practical point of view regarding computerized instruction in higher education, but it makes it difficult to unequivocally interpret the results because differences in outcomes between the conditions can be attributed to a number of possible causes. Second, although the MSLQ (Pintrich et al., 1991) is a broadly used questionnaire, the measurement of SRL by means of the MSLQ is disputable. As a self-report questionnaire the MSLQ measures SRL as an aptitude, because the items ask respondents to generalize their learning actions across situations rather than referencing singular and specific learning events while they experience them. So far there is no problem. However, it is necessary to investigate the congruity between SRL and MSLQ more in depth in future research. If discrepancies are detected, it can be considered to expand the MSLQ with scales or subscales from other proven measurement instruments, as for instance the Learning and Study Strategies Inventory (LASSI; Weinstein, Schulte, \& Palmer, 1987) and the Inventory of Learning Styles (ILS; Vermunt, 1992). Weinstein and Meyer (1996) stated that assessment of the development of SRL could best take place using a triangulation of measurements. Performance assessment is suggested to be an adequate supplementary way to record students' SRL. In performance assessments, observation of performances is seen as the means by which behavior can be registered, and assessed. In distance education settings, a problem that should be overcome is that direct observations of performances are practically impossible. Third, the conclusions we have drawn are limited to higher education adult students studying within an electronic learning environment. More research is needed to determine whether the same results are obtained in other educational settings, and with other student populations.

In summary, the results of this study contribute to the identification of instructional strategies that can help students in higher education to develop their SRL. Especially, a 
reflection protocol in which reflection prompts are combined with external feedback from a tutor appears to be a very promising strategy to foster SRL. Both, the optimization of this type of feedback, and more insight in the conditions under which peers can effectively function as external feedback providers represent important research challenges. 


\section{Acknowledgements}

With the kind cooperation of Arjan Bos (Assistant Professor at the Faculty of Psychology, Open University of the Netherlands) it was possible to conduct the experiment. Furthermore we are grateful to all participating students, to the tutors Lieke Bezemer, Brigitte DeCraene, Judith Gulikers, and Tamara van Gog, and to Jurjen Puls, Sabine Roks, and Marcel Wigman for their technical support. Finally, we want to thank three anonymous reviewers for their constructive comments. 


\section{References}

Arnold, J., Cooper, C. L., \& Robertson, I. T. (1998). Work psychology: Understanding human behavior in the workplace (Third edition). Harlow, UK: Pearson Education.

Azevedo, R., \& Cromley, J. G. (2004). Does training on self-regulated learning facilitate students' learning with hypermedia? Journal of Educational Psychology, 96, 523-535.

Azevedo, R., Cromley, J. G., \& Seibert, D. (2004). Does adaptive scaffolding facilitate students' ability to regulate their learning with hypermedia? Contemporary Educational Psychology, 29, 344-370.

Bangert-Drowns, R. L., Kulik, C. C., Kulik, J. A., \& Morgan, M. T. (1991). The instructional effect of feedback in test-like events. Review of Educational Research, 61, 213-238.

Boekaerts, M. (1997). Self-regulated learning: A new concept embraced by researchers, policy makers, educators, teachers, and students. Learning and Instruction, 7, 161-186.

Boekaerts, M. (1999). Self-regulated learning: Where are we today? International Journal of Educational Research, 31, 445-457.

Boekaerts, M. (2002). Bringing about change in the classroom: Strengths and weaknesses of the self-regulated learning approach. Learning and Instruction, 12, 589-602.

Butler, D. L. (1998). The strategic content learning approach to promoting self-regulated learning: A report of three studies. Journal of Educational Psychology, 90, 682-697.

Butler, D. L. (2003). Structuring instruction to promote self-regulated learning by adolescents and adults with learning disabilities. Exceptionality, 11, 39-60.

Butler, D. L., \& Winne, P. H. (1995). Feedback and self-regulated learning: A theoretical synthesis. Review of Educational Research, 65, 245-281.

Chi, M. T. H. (1996). Constructing self-explanations and scaffolded explanations in tutoring. Applied Cognitive Psychology, 10, 33-49. 
Chi, M. T. H., De Leeuw, N., Chiu, M. H., \& La Vancher, C. (1994). Eliciting selfexplanations improves understanding. Cognitive Science, 18, 439-477.

Cohen, J. (1998). Statistical power analysis for the behavioral sciences. Hillsdale, NJ: Lawrence Erlbaum.

Dochy, F. J. R. C., Segers, M. S. R., \& Sluijsmans, D. M. A. (1999). The use of self-, peerand co-assessment in higher education: A review. Studies in Higher Education, 24, 331350.

Ertmer, P. A., \& Newby, T. J. (1996). The expert learner: Strategic, self-regulated, and reflective. Instructional Science, 24, 1-24.

Falchikov, N. (1996). Improving learning through critical peer feedback and reflection. Different Approaches: Theory and Practice in Higher Education. Proceedings HERDSA Conference 1996. Perth, Western Australia, 8-12 July. Retrieved March 07, 2004, form http://www.herdsa.org.au/confs/1996/falchikov.html

Graesser, A. C., Person, N. K., \& Magliano, J. P. (1995). Collaborative dialogue patterns in naturalistic one-to-one tutoring. Applied Cognitive Psychology, 9, 495-522.

Johnson, D. W., \& Johnson, R. T. (1999). Learning together and alone: Cooperative, competitive and individualistic learning. Boston, MA: Allyn \& Bacon.

Kriewaldt, J. (2001). A thinking geography curriculum. Interaction, 29. Retrieved November 01, 2004, from http://www.gtav.asn.au/interaction/issues/v29n4_dec01/metacognition.htm.

Lee, A. Y., \& Hutchison, L. (1998). Improving learning from examples through reflection. Journal of Experimental Psychology: Applied, 4, 187-210.

Masui, C., \& De Corte, E. (2005). Learning to reflect and to attribute constructively as basic components of self-regulated learning. British Journal of Educational Psychology, 75, $351-372$. 
Mory, E. H. (2003). Feedback research revisited. In D. H. Jonassen (Ed.), Handbook of research for educational communications and technology: A Project of the Association for Educational Communications and Technology (2nd ed., pp. 745-783). Mahwah, NJ: Lawrence Erlbaum.

Nilson, L. B. (2003). Improving student peer feedback. College Teaching, 51, 34-38.

Pintrich, P. R. (2000). The role of goal orientation in self-regulated learning. In M. Boekaerts, P. R. Pintrich, \& M. Zeidner (Eds.), Handbook of self-regulation (pp. 451-502). San Diego, CA: Academic Press.

Pintrich, P. R. (2004). A conceptual framework for assessing motivation and self-regulated learning in college students. Educational Psychology Review, 16, 385-407.

Pintrich, P. R., Smith, D. A. F., Garcia, T., \& McKeachie, W. J. (1991). A manual for the use of the Motivated Strategies for Learning Questionnaire (MSLQ). The regents of the University of Michigan. NCRIPTAL-91-B-004.

Pintrich, P. R., Smith, D. A. F., Garcia, T., \& McKeachie, W. J. (1993). Reliability and predictive validity of the motivated strategies for learning questionnaire (MSLQ). Educational and Psychological Measurement, 53, 801-813.

Pressley, M. (1995). More about the development of self-regulation: Complex, long-term, and thoroughly social. Educational Psychologist, 30, 207-212.

Sanz de Acedo Lizarraga, M. L., Ugarte, M. D., Cardelle-Elawar, M., Iriarte, M. D., \& Sanz de Acedo Baquedano, M. T. (2003). Enhancement of self-regulation, assertiveness, and empathy. Learning and Instruction, 13, 423-439.

Schunk, D. H., \& Ertmer, P. A. (2000). Self-regulation and academic learning: Self-efficacy enhancing interventions. In M. Boekaerts, P. R. Pintrich, \& M. Zeidner (Eds.), Handbook of self-regulation (pp. 631-649). San Diego, CA: Academic Press. 
Seale, J. K., \& Cann, A. J. (2000). Reflection on-line or off-line: The role of learning technologies in encouraging students to reflect. Computers \& Education, 34, 309-320.

Sluijsmans, D. M. A. (2002). Student involvement in assessment: The training of peer assessment skills (Dissertation). Heerlen: Open University of the Netherlands.

Sobrol, D. T. (2000). An appraisal of medical students' reflection-in-learning. Medical Education, 34, 182-187.

Strijbos, J-W. (2004). The effects of roles on computer supported collaborative learning (Dissertation). Heerlen: Open University of the Netherlands.

Strijbos, J-W., Kirschner, P. A., \& Martens, R. L. (2004). What we know about CSCL: And what we do not (but need to) know about CSCL. In J-W. Strijbos, P. A. Kirschner, \& R. L. Martens (Eds.), What we know about CSCL: And implementing it in higher education (pp. 245-259). Boston, MA: Kluwer Academic.

Thiede, K. W., Anderson, M. C. M., \& Therriault, D. (2003). Accuracy of metacognitive monitoring affects learning of texts. Journal of Educational Psychology, 95, 66-73. Van den Boom, G., Paas, F., van Merriënboer, J. J. G., \& van Gog, T. (2004). Reflection prompts and tutor feedback in a web-based learning environment: Effects on students' self-regulated learning competence. Computers in Human Behavior, 20, 551-567.

Van Manen, M. (1991). Reflectivity and the pedagogical moment: The normativity of pedagogical thinking and acting. Journal of Curriculum Studies, 23, 507-536.

Van Merriënboer, J. J. G. (1997). Training complex cognitive skills: A four-component instructional design model for technical training. Englewood Cliffs, NJ: Educational Technology Publications.

Van Velzen, J. H. (2002). Instruction and self-regulated learning: Promoting students' (self-) reflective thinking (Dissertation). Leiden, The Netherlands: Universiteit Leiden. 
Vermunt, J. D. H. M. (1992). Leerstijlen en sturen van leerprocessen in het hoger onderwijs: naar procesgerichte instructie in zelfstandig denken [Learning styles and regulation in higher education: towards process-oriented instruction in autonomous thinking] (Dissertation). Amsterdam, The Netherlands: Swets \& Zeitlinger.

Vermunt, J. D. (1998). The regulation of constructive learning processes. British Journal of Educational Psychology, 68, 149-171.

Vermunt, J. D. (2000). Over de kwaliteit van het leren [About quality of learning]. In W. Gijselaars \& J. D. Vermunt (Eds.), Studeren voor nieuwe geleerden [Studying for new scholars] (pp. 37-61). Maastricht, The Netherlands: Universiteit Maastricht.

Vermunt, J. D., \& Verloop, N. (1999). Congruence and friction between learning and teaching. Learning and Instruction, 9, 257-280.

Von Wright, J. (1992). Reflections on reflection. Learning and Instruction, 2, 59-68.

Weinstein, C. E., Schulte, A., \& Palmer, D. (1987). LASSI: Learning and study strategies inventory. Clearwater, FL: H\&H Publishing.

Weinstein, C. E., \& Meyer, D. K. (1996). Learning strategies: Teaching and assessing. In E. De Corte \& F. E. Weinert (Eds.), International encyclopedia of developmental and instructional psychology (pp. 423-427). Oxford, UK: Elsevier Science.

Winne, P. H., \& Hadwin, A. F. (1998). Studying as self-regulated learning. In D. J. Hacker, J. Dunlosky, \& A. C. Graesser (Eds.), Metacognition in educational theory and practice (pp. 277-304). Mahwah, NJ: Lawrence Erlbaum.

Winne, P. H., \& Perry, N. E. (2000). Measuring self-regulated learning. In M. Boekaerts, P. R. Pintrich, \& M. Zeidner (Eds.), Handbook of self-regulation (pp. 531-566). San Diego, CA: Academic Press.

Zimmerman, B. J. (1998). Developing self-fulfilling cycles of academic regulation: An analysis of exemplary instructional models. In D. H. Schunk \& B. J. Zimmerman (Eds.), 
Self-regulated learning: From teaching to self-reflective practice (pp. 1-19). New York: Guilford Press.

Zimmerman, B. J. (2001). Theories of self-regulated learning and academic achievement: An overview and analysis. In B. J. Zimmerman \& D. H. Schunk (Eds.), Self-regulated learning and academic achievement (pp. 1-37). Mahwah, NJ: Lawrence Erlbaum.

Zimmerman, B. J ., \& Schunk, D. H. (2001). Reflections on theories, identities, and actions of self-regulated learners. In B. J. Zimmerman \& D. H. Schunk (Eds.), Self-regulated learning and academic achievement: Theoretical perspectives (pp. 289-307). Mahwah, NJ: Lawrence Erlbaum. 
Table 1

Scheme of the Study tasks, the RP, and Related SRL Aspects

\begin{tabular}{|c|c|c|c|}
\hline $\begin{array}{l}\text { Study } \\
\text { task }\end{array}$ & Theme of the Study task & Reflection Prompts & $\mathrm{RP}$ is focused on SRL aspect \\
\hline 1 & $\begin{array}{l}\text { Concepts of the person in work } \\
\text { psychology and Work psychology: its } \\
\text { origins, subject matter and research } \\
\text { techniques }\end{array}$ & $\begin{array}{l}1 \text { (At the start of study task 1) Did you familiarize yourself with the } \\
\text { course as a whole? Why and How? } \\
2 \text { (At the end of study task 1) Did you plan your study of the course? If } \\
\text { you did: What are your experiences until now? Are you on scheme or } \\
\text { did you deviate? }\end{array}$ & $\begin{array}{l}\text { Starting phase: Orienting: Task } \\
\text { diagnoses } \\
\text { Starting phase: Planning }\end{array}$ \\
\hline 2 & $\begin{array}{l}\text { Individual differences and Personnel } \\
\text { selection }\end{array}$ & $\begin{array}{l}3 \text { Which learning strategies did you use in studying this study task? } \\
\text { What are your experiences with the strategies you used? }\end{array}$ & $\begin{array}{l}\text { Performing phase: Monitoring and } \\
\text { adjusting: Task aspects: Cognitive } \\
\text { processing strategies }\end{array}$ \\
\hline 3 & $\begin{array}{l}\text { Attitudes at work, Work behavior, and } \\
\text { approaches to work motivation }\end{array}$ & $\begin{array}{l}4 \text { What is your motivation in regard of studying this course? And what } \\
\text { are your experiences with regard to the influence of your motivation on } \\
\text { your study process? }\end{array}$ & $\begin{array}{l}\text { Performing phase: Monitoring and } \\
\text { adjusting: Self aspects: Motivation }\end{array}$ \\
\hline 4 & $\begin{array}{l}\text { Training and learning at work, and Careers } \\
\text { and career management }\end{array}$ & $\begin{array}{l}5 \text { How about your planning? Are you on schedule? If not, what are the } \\
\text { reasons? } \\
\text { Did you plan the date of your exam already? Is that attainable? }\end{array}$ & $\begin{array}{l}\text { Performing phase: Monitoring and } \\
\text { adjusting: Planning aspects }\end{array}$ \\
\hline 5 & $\begin{array}{l}\text { Work, Psychological well-being, and } \\
\text { stress at work }\end{array}$ & $\begin{array}{l}6 \text { Are there any personal or situational factors that are of influence for } \\
\text { your study? Which? How? }\end{array}$ & $\begin{array}{l}\text { Performing phase: Monitoring and } \\
\text { adjusting: Self and Contextual aspects }\end{array}$ \\
\hline 6 & $\begin{array}{l}\text { Minority groups at work, Perceiving } \\
\text { people, teams and groups at work, and } \\
\text { leadership }\end{array}$ & $\begin{array}{l}7 \text { Do you always select the most suitable learning strategy for the study } \\
\text { tasks? Or do you study always in the same manner? }\end{array}$ & $\begin{array}{l}\text { Performing phase: Monitoring and } \\
\text { adjusting: Task aspects: Cognitive } \\
\text { processing strategies }\end{array}$ \\
\hline \multirow[t]{2}{*}{7} & $\begin{array}{l}\text { Work organizations: Cultures, Job } \\
\text { redesign, and organizational change }\end{array}$ & $\begin{array}{l}8 \text { Looking back to the learning goals of the course: what about your } \\
\text { Feeling of knowing? }\end{array}$ & $\begin{array}{l}\text { Finishing phase: Evaluating: Task } \\
\text { aspects: Learning goals and Task } \\
\text { performance }\end{array}$ \\
\hline & & $\begin{array}{l}9 \text { If you consider a next course: Will you study it in the same way, or } \\
\text { are there things that you will do in a different way? What and Why? }\end{array}$ & $\begin{array}{l}\text { Finishing phase: Evaluating: Task, Self, } \\
\text { and Contextual aspects }\end{array}$ \\
\hline
\end{tabular}


Table 2

MSLQ Scales, Subscales, and Reliability

\begin{tabular}{|c|c|c|}
\hline $\begin{array}{l}\text { Scales, Subscales, and number of items } \\
\text { in the Dutch version a }\end{array}$ & $\begin{array}{l}\text { Cronbach's alpha } \\
\text { Pintrich et al. }\end{array}$ & $\begin{array}{l}\text { Cronbach's alpha } \\
\text { Dutch version }\end{array}$ \\
\hline \multicolumn{3}{|c|}{ Motivation Section } \\
\hline Value scale & -- & .65 \\
\hline Intrinsic goal orientation (3 items) & .74 & .47 \\
\hline Extrinsic goal orientation (4 items) & .62 & .65 \\
\hline Task value (6 items) & .90 & .63 \\
\hline Expectancy scale & -- & .85 \\
\hline Control of learning beliefs (4 items) & .68 & .46 \\
\hline Self-efficacy for learning and performance ( 8 items) & .93 & .88 \\
\hline Test anxiety scale & -- & .76 \\
\hline Test anxiety (5 items) & .80 & .76 \\
\hline \multicolumn{3}{|c|}{ Learning Strategies Section } \\
\hline Cognitive strategy scale & -- & .81 \\
\hline Rehearsal (4 items) & .69 & .74 \\
\hline Elaboration (6 items) & .75 & .69 \\
\hline Organization (4 items) & .64 & .76 \\
\hline Critical thinking (5 items) & .80 & .72 \\
\hline Metacognitive strategy scale & -- & .71 \\
\hline Metacognitive self-regulation (11 items) & .79 & .71 \\
\hline Resource management strategy scale & -- & .79 \\
\hline Time and study environment ( 8 items) & .76 & .76 \\
\hline Effort regulation (4 items) & .69 & .69 \\
\hline Peer learning (3 items) & .76 & .49 \\
\hline Help seeking (4 items) & .52 & .69 \\
\hline
\end{tabular}

${ }^{\mathrm{a}}$ The original MSLQ contains 81 items; Item 24 and 57 are removed in the Dutch version, so this version contains 79 items. ${ }^{b}$ Alpha's for the six compound scales are not reported by Pintrich et al. (1991, 1993). 
Table 3

Participation in the Electronic Reflective Activities

\begin{tabular}{|c|c|c|c|c|}
\hline \multirow[b]{2}{*}{$\begin{array}{l}\text { Reflection } \\
\text { Prompt }\end{array}$} & \multicolumn{2}{|c|}{ Peer feedback condition $(n=16)$} & \multicolumn{2}{|c|}{ Tutor feedback condition $(n=15)$} \\
\hline & $\begin{array}{c}\text { Initial reflective } \\
\text { messages }\end{array}$ & $\begin{array}{l}\text { Messages in reflective } \\
\text { dialogues }\end{array}$ & $\begin{array}{c}\text { Initial reflective } \\
\text { messages }\end{array}$ & $\begin{array}{c}\text { Messages in reflective } \\
\text { dialogues }\end{array}$ \\
\hline 1 & 13 & 13 & 15 & 60 \\
\hline 2 & 12 & 16 & 15 & 47 \\
\hline 3 & 12 & 13 & 14 & 45 \\
\hline 4 & 13 & 14 & 15 & 51 \\
\hline 5 & 12 & 12 & 15 & 40 \\
\hline 6 & 11 & 15 & 15 & 45 \\
\hline 7 & 11 & 11 & 15 & 50 \\
\hline 8 & 12 & 12 & 14 & 41 \\
\hline 9 & 11 & 12 & 14 & 37 \\
\hline$\Sigma$ & 107 & 118 & 132 & 416 \\
\hline$M$ & 6.7 & 7.4 & 8.8 & 27.7 \\
\hline
\end{tabular}


Elicited Reflections 41

Table 4

Means and Standard Deviations of Measures of MSLQ, and Course Related Scores

\begin{tabular}{|c|c|c|c|c|c|c|}
\hline & \multicolumn{2}{|c|}{ Control condition $^{\mathrm{a}}$} & \multicolumn{2}{|c|}{ Peer feedback condition ${ }^{\mathrm{b}}$} & \multicolumn{2}{|c|}{ Tutor feedback condition $^{\mathrm{c}}$} \\
\hline & $M$ & $S D$ & $M$ & $S D$ & $M$ & $S D$ \\
\hline \multicolumn{7}{|c|}{ MSLQ Pretest } \\
\hline Value scale & 5.58 & 0.62 & 5.43 & 0.43 & 5.49 & 0.58 \\
\hline Expectancy scale & 4.98 & 0.85 & 5.24 & 0.71 & 5.01 & 0.74 \\
\hline Test anxiety scale & 3.54 & 1.33 & 3.75 & 1.41 & 3.58 & 1.02 \\
\hline Cognitive strategy scale & 4.76 & 0.60 & 5.16 & 0.51 & 5.20 & 0,87 \\
\hline Metacognitive strategy scale & 4.99 & 0.83 & 5.35 & 0.87 & 5.41 & 0.81 \\
\hline Resource management strategy scale & 4.28 & 0.92 & 4.46 & 0.69 & 4.30 & 0.97 \\
\hline \multicolumn{7}{|c|}{ MSLQ Difference Scores } \\
\hline Value scale & -0.26 & 0.36 & 0.14 & 0.41 & 0.13 & 0.38 \\
\hline Expectancy scale & 0.19 & 0.69 & -0.05 & 0.59 & 0.06 & 0.37 \\
\hline Test anxiety scale & 0.26 & 0.65 & 0.24 & 0.71 & -0.35 & 0.89 \\
\hline Cognitive strategy scale & -0.11 & 0.56 & -0.12 & 0.53 & -0.03 & 0.57 \\
\hline Metacognitive strategy scale & 0.09 & 0.61 & -0.10 & 0.62 & 0.09 & 0.62 \\
\hline Resource management strategy scale & -0.15 & 0.58 & -0.19 & 0.58 & 0.05 & 0.59 \\
\hline \multicolumn{7}{|c|}{ Course Related Scores } \\
\hline Learning outcome scores ${ }^{\mathrm{d}}$ & 5.94 & 1.63 & 5.75 & 1.34 & 6.93 & 1.09 \\
\hline Time-on-task (study load in hours) & 105 & 64 & 123 & 61 & 99 & 28 \\
\hline Overall evaluative opinion about the course & 6.88 & 0.76 & 6.89 & 0.59 & 7.02 & 0.86 \\
\hline \multicolumn{7}{|l|}{ "Introduction to Work Psychology" d } \\
\hline $\begin{array}{l}\text { Overall evaluative opinion about the experienced } \\
\text { feedback modality }{ }^{\mathrm{d}}\end{array}$ & -- & -- & 4.60 & 2.03 & 8.27 & 1.22 \\
\hline
\end{tabular}

${ }^{\mathrm{a}} n=18 .{ }^{\mathrm{b}} n=16 .{ }^{\mathrm{c}} n=15 .{ }^{\mathrm{d}}$ Score on a 10 -point scale ( $1=$ minimum, $10=$ maximum $)$. 
Table 5

Scores on Evaluation Items Subdivided for the Peer and Tutor Feedback Condition ${ }^{a}$

$M \quad S D$

\section{Peer Feedback Condition}

It was useful for me to post my reflections to the peer newsgroup.

I appreciated the possibility to read the reflections of my peer students in the newsgroup.

I frequently reacted on the reflections of my peer students.

$2.80 \quad 1.26$

Reflections of my peer students urged me on thinking about my own studying.

I would have liked to receive more feedback on my reflections from my peer students.

I frequently used the peer student newsgroup.

I prefer the option to have a peer student newsgroup on future occasions.

$3.73 \quad 1.53$

The reflection prompts were useful for me.

$1.87 \quad 0.92$

The reflection prompts did stimulate me to reflect on my study process.

The reflection prompts did distract me from my study.

$3.60 \quad 1.24$

$2.40 \quad 1.59$

It was useful for me to have the opportunity to communicate with a tutor.

I appreciated the tutor feedback on my reflections.

The tutor feedback on my reflections distracted me from studying.

The tutor feedback on my reflections urged me on thinking about my studying.

I prefer the option to have a tutor on future occasions

With reference to the reflection prompts I also 'talked' with my tutor about other things than my study.

The reflection prompts were useful for me.

The reflection prompts did stimulate me to reflect on my study process. 
Figure Captions

Figure 1. A decomposition of SRL. 
Elicited Reflections 44

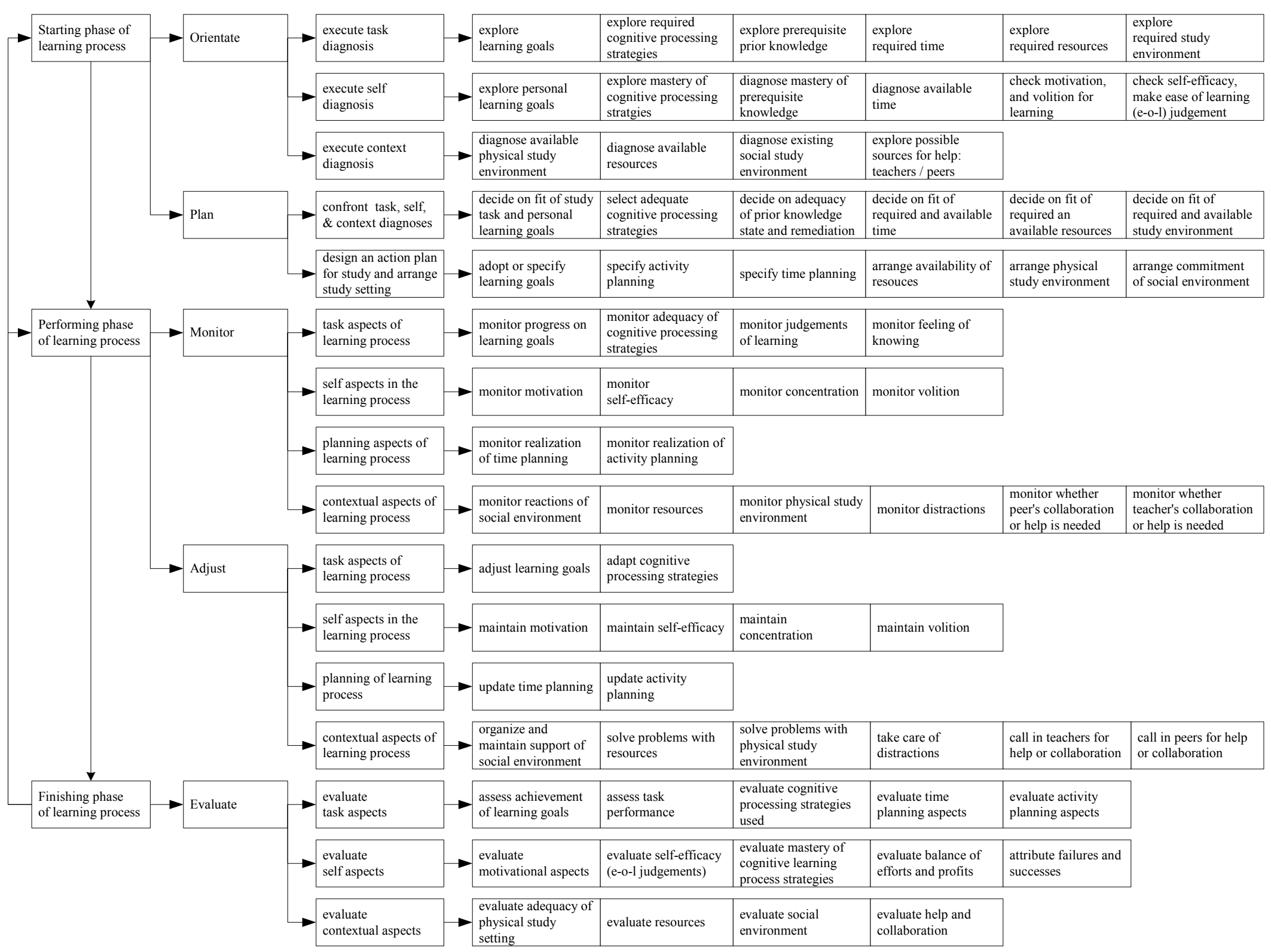

